\title{
Bruce Greyson Responds
}

To the Editor:

I appreciate Karlis Osis' interest in NDErs' satisfaction with life, and his insights into possible sampling bias in my work. Osis, a pioneer in the research of out-of-body experiences and deathbed visions, questioned whether the similar ratings of my three study groups-NDErs, individuals who had some close to death without NDEs, and individuals who had never come close to death-might have been due to their all having been drawn from the IANDS membership, who may not be representative of other NDErs or the general population. The fact that my findings replicated those of Melodie Olson and Peggy Dulaney's study (1993) of an unselected sample of elderly NDErs and nonNDErs makes it somewhat less plausible that they were due solely to sampling bias. Nevertheless, Osis' point is valid that the IANDS membership may be so homogeneous in certain attitudes as to obscure differences between NDErs and nonNDErs that would be obvious among non-IANDS members.

Another possible explanation for my negative results has recently been brought to my attention. Bill Bingham (personal communication, November 3, 1994), coordinator of the Houston chapter of the Friends of IANDS, suggested that in assessing their satisfaction with life, NDErs and nonNDErs may judge their current situation by very different yardsticks. NonNDErs compare their current existence to an idealized earthly life that may differ from their current life only 
in small details. NDErs, on the other hand, compare their current existence to the transcendent realm of the NDE; by that criterion, Bingham suggested, few NDErs would say they were "satisfied" with life. While the wording of the Satisfaction With Life Scale implied a comparison with "what might have been" in this earthly realm, the contrast to the unearthly dimension could certainly have influenced NDErs' ratings. In the interest of using a scale that had documented reliability and validity, I may have selected one that might be insensitive to NDErs' particular viewpoint, and that may well have contributed to my failure to find a difference between groups.

Osis' and Bingham's comments, taken together, point out the need for a more definitive study of randomly selected NDErs and control groups in which criteria for judging life satisfaction are spelled out more clearly.

\section{References}

Olson, M., and Dulaney, P. (1993). Life satisfaction, life review, and near-death experiences in the elderly. Journal of Holistic Nursing, 11, 368-382.

Bruce Greyson, M.D. Division of Personality Studies Department of Psychiatric Medicine Box 152, Health Sciences Center University of Virginia Charlottesville, VA 22908 